\title{
OPERATION OF WASTE-TO-ENERGY-PLANT OPTIMISATIONS BY USING DESIGN EXPLORATION
}

\author{
Kapitler, M.*; Samec, N.* \& Kokalj, F.* \\ *University of Maribor, Faculty of Mechanical Engineering, Smetanova 17, SI-2000 Maribor, \\ Slovenia \\ E-mail: miran.kapitler@uni-mb.si
}

\begin{abstract}
:
Nowadays, a part of Municipal Solid Waste (MSW) of higher calorific value is usually used as a fuel in Waste-To-Energy-Plant (WTEP) which uses bed combustion process in a grate furnace. The properties and structure of MSW are very variable, so the complete combustion and emissions on the reasonable level are often very hard to achieve. The Computational Fluid Dynamics (CFD) with different CFD codes is often used to analyse the situation in the WTEP. In this paper, the CFD simulation within ANSYS 13.0 software package and in WORKBENCH 2.0 environment is used and supplementary optimisation's methods are employed by using design explorer approach to achieve the target - optimised values of the input and output parameters which have been defined in order to indicate the complete combustion in the furnace. Furthermore, input and output parameters interaction can be found and presented and measured. On this basis, the optimal operating conditions and optimal combustion chamber dimensions are established through decision support systems in order to assure the complete combustion process with minimal emissions on the environment. Moreover, these requirements should be taken into account to enhance the operation conditions in the existing furnace or in research, development or project phase. In this way, the costs and time in these activities can be reduced. This approach has benefits because it can be used in other furnaces which use other fuels such as biomass, waste-oils or coal.
\end{abstract}

Key Words: Municipal Solid Waste (MSW), Computational Fluid Dynamics (CFD), Grate Combustion, Optimisation, Decision Support

\section{INTRODUCTION}

Using MSW as a fuel in WTEP is nowadays much widened. The characteristics of the MSW are very variable, so the combustion there are very specific due to the specific phase of the combustion and also characteristics of fuel (MSW) which depend on waste composition like proximate and ultimate analyze, season of the year, primary and secondary inlet air velocity and many other parameters which change all the time in some frames. The combustion of MSW in the gaseous phase combustion has many phases like moisture evaporation, waste devolatilisation, combustion of volatiles, mixing and fixed carbon combustion during heterogeneous chemical reactions. In this way, the measurements of flue gases are needed to find out the components and the level of complete combustion [1]-[2].

The mathematical models of boundary conditions definition were developed so the review with advantage and disadvantage can be seen [3]. Some of the authors have developed their own code such as FLIC [4]-[7] to find out combustion products distribution in the gaseous phase above the fuel bed along the moving grate. They have reported about their successful simulations results which were matched with the data which were measured so they models can be verified [4]-[13]. Some of them discovered which models should be used to achieve the best results [13].

Present paper deals, not only with the simulation of the MSW combustion, with the optimisation of operating conditions and optimal geometry of combustion chamber [14]. 
This paper is focused on the main theme, optimization, so the CFD details were not in the first plan.

\section{COMBUSTION MODELLING BY USING CFD}

First of all, the classic CDF is performed. It means that the relevant geometric model of WTEP is drawn in natural scale, and the meshing is optimised (Figure 1).

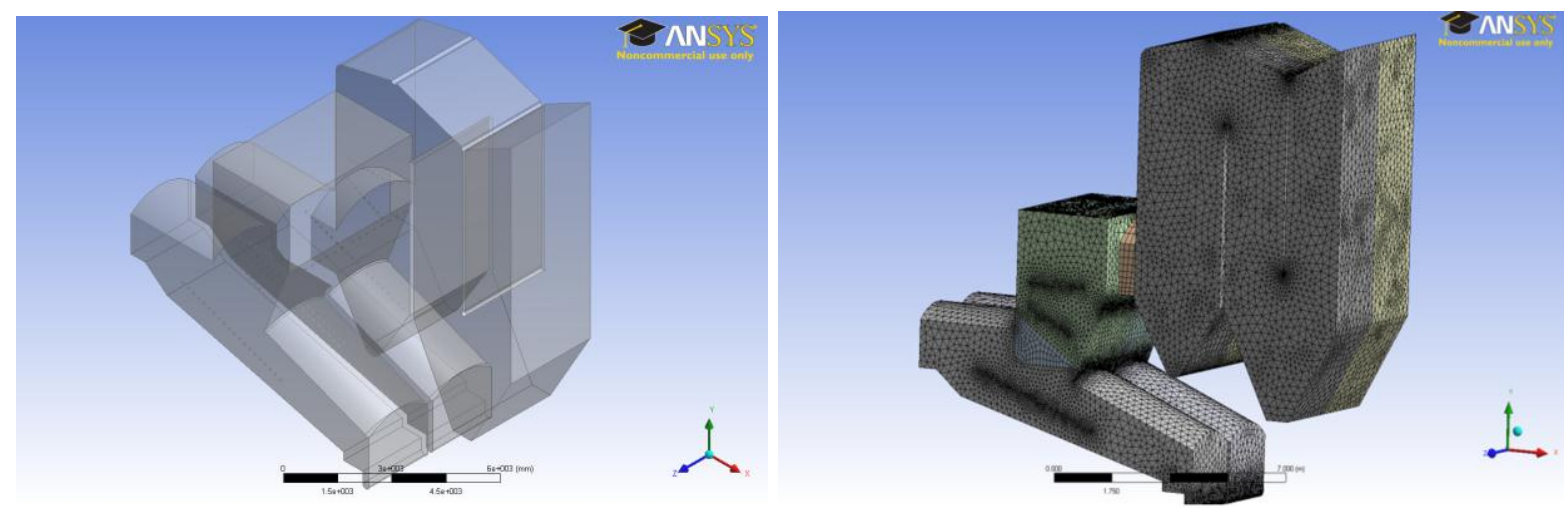

Figure 1: 3-D geometry plan of WTEP (left) and it's meshing in 3-D view (right).

Furthermore, the relevant turbulent, combustion, radiation and particle tracking model and other main setting are used (Table I).

Table I: Applied main settings review.

\begin{tabular}{|c|c|}
\hline Submodel/Phenomenon & Type/Approach \\
\hline Turbulence model & k - epsilon $(\mathrm{k}-\varepsilon)$ \\
\hline Combustion model & Eddy Dissipation \\
\hline Thermal radiation model & P1 \\
\hline Spectral model & Gray \\
\hline Heat transfer model & Fluid Dependent \\
\hline Fluid pair: methane air mixture MSW | ash & Particle Coupling $=$ Fully Coupled \\
\hline Interphase heat transfer & Ranz Marshall \\
\hline Interphase thermal radiation & Opaque; Emissivity = 1 \\
\hline Momentum transfer: drag force & Schiller Naumann \\
\hline
\end{tabular}

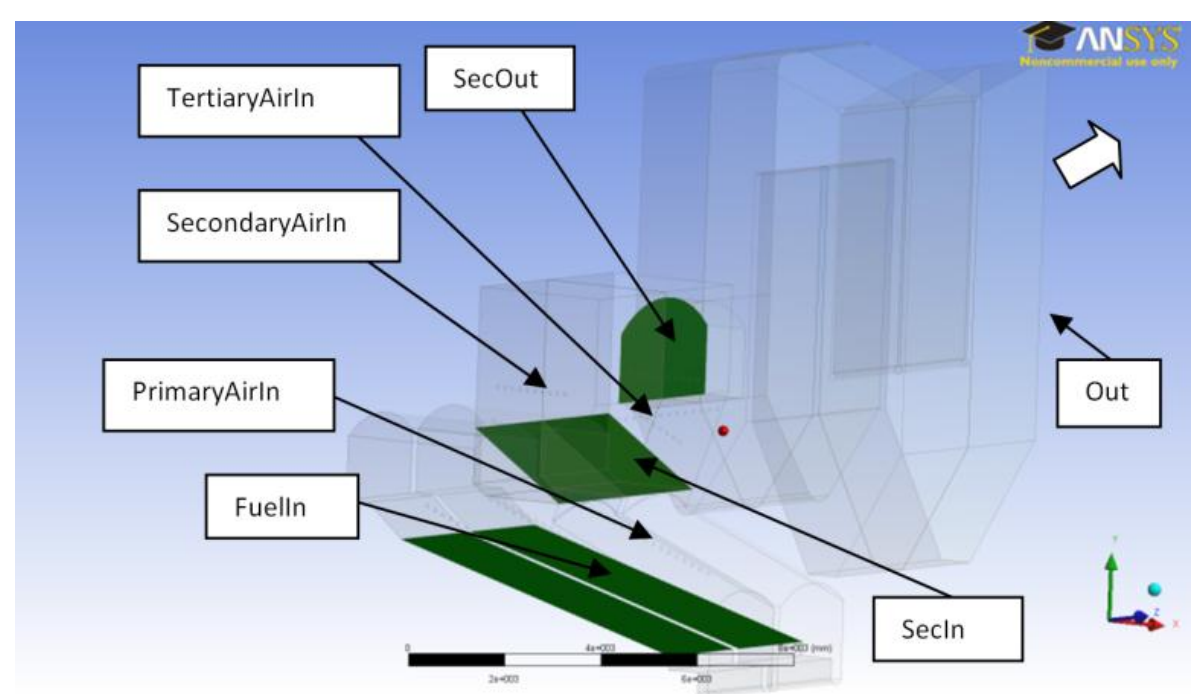

Figure 2: Boundary areas review. 
In next step, the boundary conditions and boundary areas (Figure 2) are defined with initial input values and the convergent solution is calculated. In this way, the first design point has been obtained, meaning a set of input parameter values and corresponding output parameter values associated with an individual parameterized project definition.

Now that is time to define the input and output parameters. Input parameter can be physical values or geometry values which vary, and on the other hand, output parameters can be defined as quality and quantity processes indicators, and they have been calculated through each combination of input parameters. In our case, the following input and output parameters (Table II) have been created:

Table II: Input and output parameters review.

\begin{tabular}{|c|l|c|l|c|}
\hline$\#$ & Parameter mark & $\begin{array}{c}\text { Parameter } \\
\text { type }\end{array}$ & \multicolumn{1}{|c|}{ Parameter description } & Unit \\
\hline P1 & Visina2 & input & Secondary air inlet height & {$[\mathrm{mm}]$} \\
\hline P2 & Zavesa & input & Outlet height (outlet area largenes) & {$[\mathrm{mm}]$} \\
\hline P3 & KONSTCOY & input & $\begin{array}{l}\text { Added mass fraction (MFR) value of carbon } \\
\text { monoxide (CO)at fuel input }\end{array}$ & {$[-]$} \\
\hline P4 & KONSTTY & input & Added temperature value at fuel input & {$[\mathrm{K}]$} \\
\hline P5 & InSecAirVelocity2 & input & Secondary air inlet velocity & {$[\mathrm{m} / \mathrm{s}]$} \\
\hline P6 & COOut & output & CO average value of MRF at outlet & {$[-]$} \\
\hline P7 & O2Out & output & O2 average value of MRF at outlet & {$[-]$} \\
\hline P8 & TempDiffOut & output & Temperature difference at outlet & {$[\mathrm{K}]$} \\
\hline P9 & AshTempMax & output & Maximal ash temperature & {$[\mathrm{K}]$} \\
\hline P10 & AshTime & output & Average ash travelling time & {$[\mathrm{s}]$} \\
\hline P11 & CH4Out & output & CH4 average value of MRF at outlet & {$[-]$} \\
\hline P12 & H2Out & output & H2 average value of MRF at outlet & {$[-]$} \\
\hline P13 & CO2Out & output & MRF average value of CO2 at outlet & {$[-]$} \\
\hline P14 & TempOut & output & Outlet temperature & {$[\mathrm{K}]$} \\
\hline P15 & NOOut & output & $\begin{array}{l}\text { Nitrogen monoxide (NO) average value of MRF } \\
\text { at outlet }\end{array}$ & {$[-]$} \\
\hline P16 & COSecln & output & $\begin{array}{l}\text { CO average value of MRF at secondary } \\
\text { chamber inlet }\end{array}$ & {$[-]$} \\
\hline P17 & COSecOut & output & $\begin{array}{l}\text { CO average value of MRF at secondary } \\
\text { chamber outlet }\end{array}$ & {$[-]$} \\
\hline P18 & H2OOut & output & H2O average value of MRF at outlet & {$[-]$} \\
\hline P19 & O2Secln & output & $\begin{array}{l}\text { O2 average value of MRF at secondary } \\
\text { chamber inlet }\end{array}$ & {$[-]$} \\
\hline P20 & O2SecOut & output & $\begin{array}{l}\text { O2 average value of MRF at secondary } \\
\text { chamber outlet }\end{array}$ & {$[-]$} \\
\hline
\end{tabular}

On the Figure 3 input parameters P1-Visina and P2-Zavesa can be seen. When the P1 increases the row on secondary air inlet is higher, and when the P2 increases the area on the outlet also increases. These two geometry values have also direct influence on the output parameters in the continuation these influence beside the other physics values of input parameters will be discovered. 

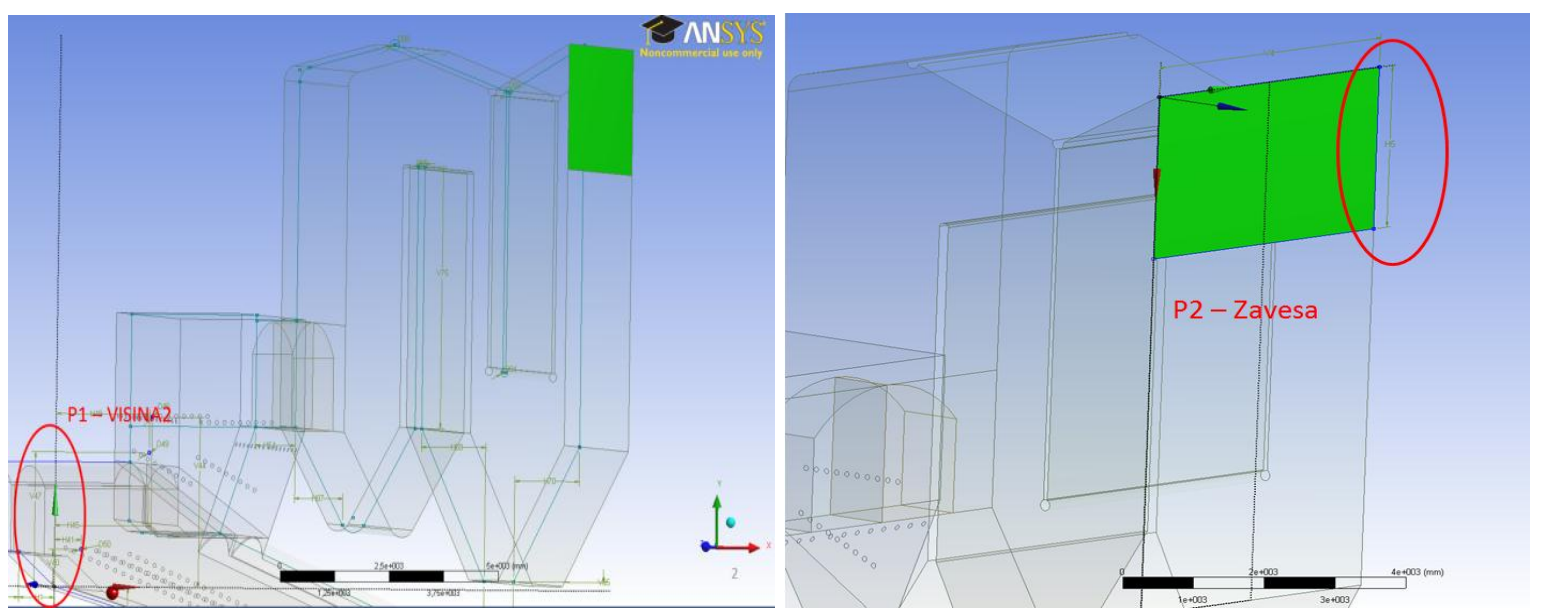

Figure 3: Input parameters P1-Visina 2 (left) and P2-Zavesa review.

\section{GOAL DRIVEN OPTIMISATON}

\subsection{Optimisation course and methods}

In this paper, the optimisation is performed with the software package named DesignXplorer which works in Workbench 2.0 environment. DesignXplorer is a tool that uses response surfaces to efficiently explore the solution space. With this tool it is possible to:

- explore and understand the performance at other design or operating conditions,

- find the conditions which give the best performance

- determinate conditions which give the best performance

- explore the robustness design

As it has been mentioned, the input and output parameter are needed to be created and the initial model with initial input parameters value has to be convergent calculated.

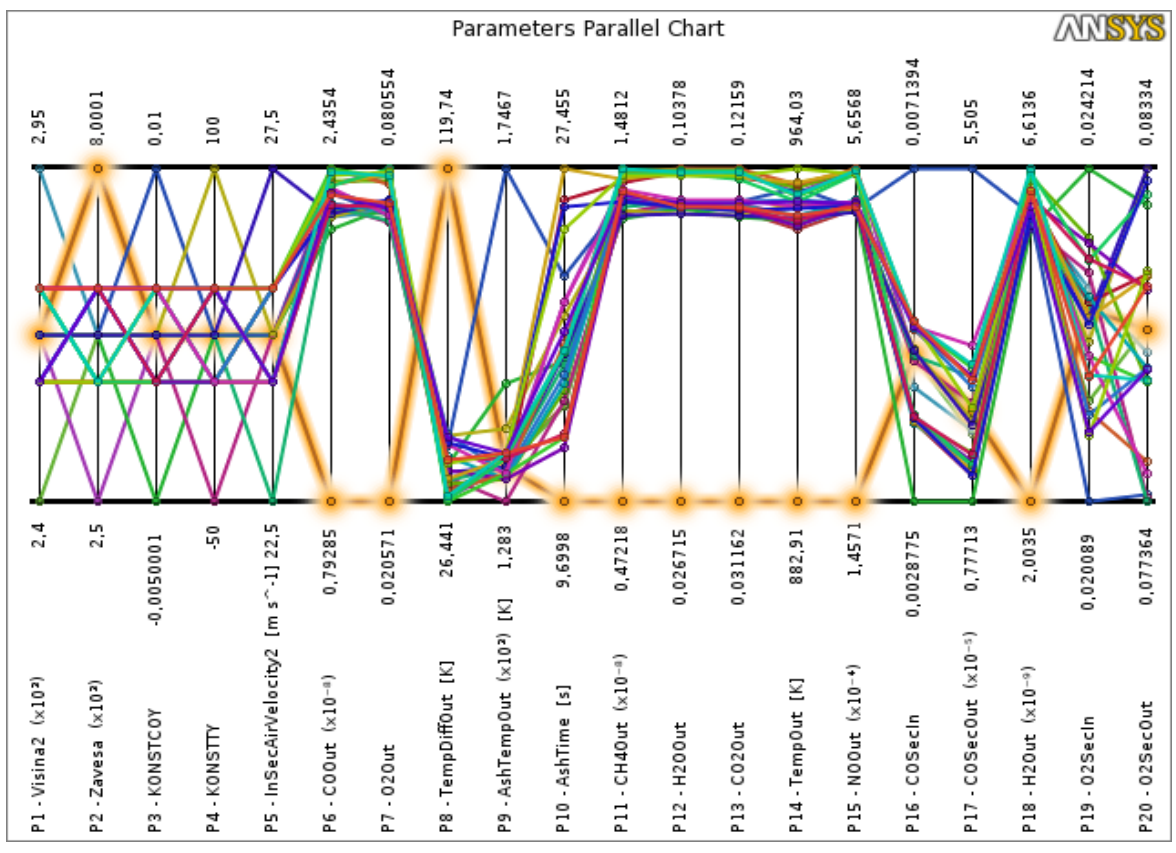

Figure 4: Parameters parallel chart of 27 different design points with relevant input and output parameters. 
The next step is to create a response charts in surface form. After inserting a Response Surface system in the project, it is necessary to define the design space by diving minimum and maximum values to be considered for each of the input variables. Based on this information, The Design of Experiments (DOE) part of the Response Surface system will create the design of sampling. This sampling depends upon the choice made for the DOE scheme. In our case with 5 input parameters the different design points have to be convergent calculated. That means that the 27 combination of input parameter values have to be calculated. In our case, when the different geometry values are used, 3 dimensions geometry model has to be re-drawn and re-meshed. On the Fig. 4 parameters parallel chart of 27 different design points with relevant input in corresponding output parameters value are shown.

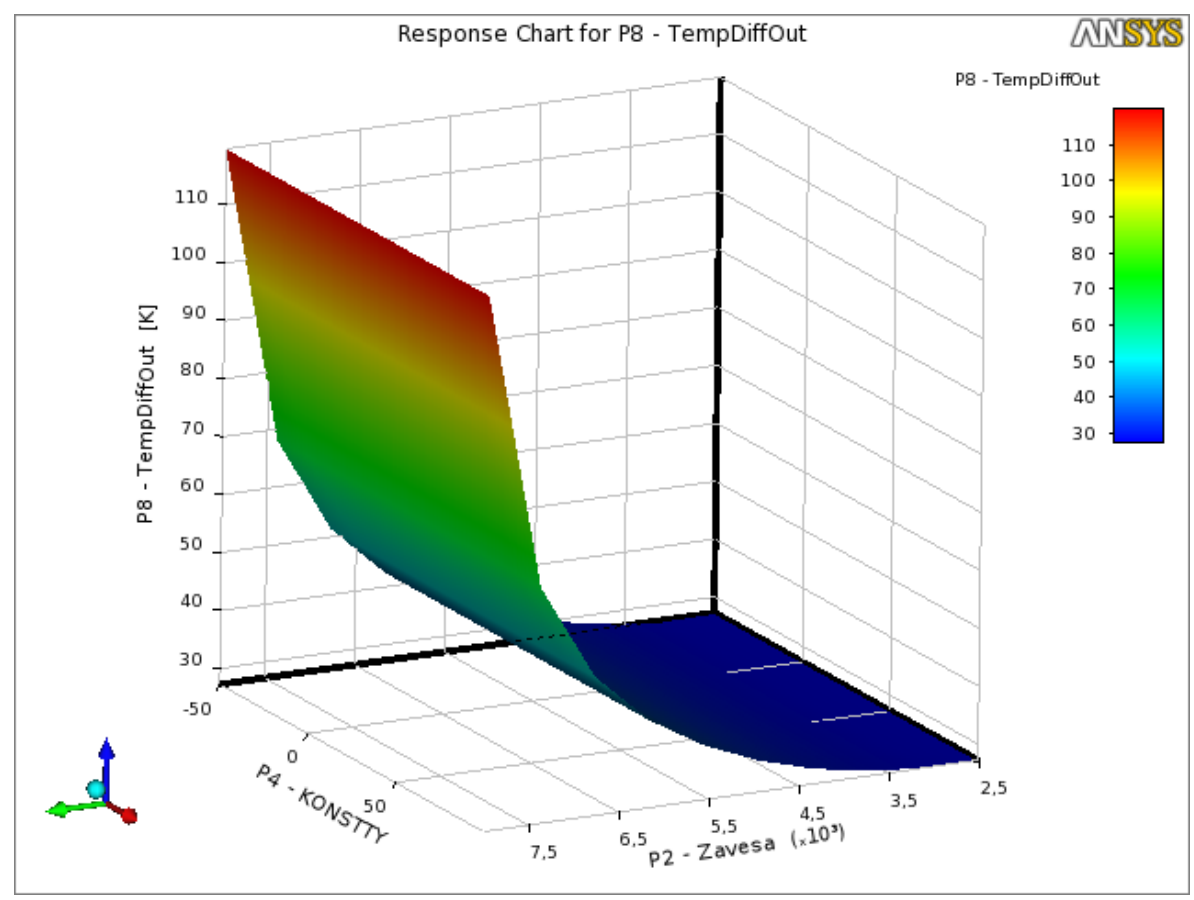

Figure 5: Response surface for input parameters P4 and P2 with output parameter P8.

Once the DOE has been updated, a response surface is created for each output parameter on the whole input values area (Figure 5). Figure 5 shows the impact of input parameters P2Zavesa and P4-KONSTTY, respectively, on output parameters P8-TempDiffOut. It can be seen; when the P2 increases the temperature difference increases P8 from $30 \mathrm{~K}$ to $120 \mathrm{~K}$. On the other hand, input parameter has no influence on output temperature difference on outletoutput parameter P8.

A response surface is an approximation of the response of the system. Its accuracy depends on several factors: complexity of the variations of the output parameters, number of points in the original DOE, and choice of the response surface type. Several main types several main types of response surfaces are available in design exploration. As a starting point, the Standard Response Surface (based on a modified quadratic formulation) will provide satisfying results when the variations of the output parameters is mild, while the Kriging scheme will be used for stronger variations.

After the response surfaces have been computed, the design can be thoroughly investigated using a variety of graphical and numerical tools, and valid design points identified by optimization techniques. The response surfaces will provide curves or surfaces that show the variation of one output parameter with respect to one or two input parameters at a time. These curves/surfaces also are dependent on the response point.

Usually, the investigation will start with the sensitivity graphs. This bar or pie chart will graphically show how much the output parameters are locally influenced by the input parameters around a given response point. Note that varying the location of the response 
point may provide totally different graphs. Thinking of the hill/valley analogy, if the response point is in a flat valley, the influence of the input parameters will be small. If the point is at the top of a steep hill, the influence of the parameters will be strong. The sensitivity graphs provide the first indication about the relative influence of the input parameters.

Both sensitivity charts and response surfaces are key tools for the analyst to be able to answer the "What-if" questions that e.g.: "What parameter should we change if we want to reduce the cost?"

Design exploration provides additional tools to identify design candidates. While they could be determined by a thorough investigation of the curves, it might be convenient to be guided automatically to some interesting candidates. Access to optimization techniques that will find design candidates from the response surfaces is provided by the Goal Driven Optimization (GDO) systems. These systems can be dragged and dropped over an existing response surface system so as to share this portion of the data. Several GDO systems can be inserted in the project, which is useful if several hypotheses are to be analyzed. To find out the right candidates, the decisions support system, which is in chapter 3.2 further discussed, will be performed.

Goal driven optimization (GDO) is a constrained, multi-objective optimization technique in which the best possible designs are obtained from sample set given the objectives you set from parameters. GDO can be used for design optimization in three ways: the screening, the Multi-Objective Generic Algorithm (MOGA) approach and the Non-Linear Programming by Quadratic Lagrangian approach (NLPQL). The screening approach is a non-iterative direct sampling method by a quasi-random number generator based on Hammersley algorithm. Te results of this screening method are shown in Fig. 6. MOGA approach is an iterative MultiObjective Genetic Algorithm, which can optimize problems with continuous input parameters. NLPQL is a gradient based single objective optimizer which is based mathematical optimization algorithm developed by Klaus Schittkowski.

GDO has more possible objectives and they are: no-objective, minimize, maximize, target value which is less or equal and grate or equal the input target value. The importance of the parameter is default, lower and higher (Table III).

Table III: Goal driven optimization settings review.

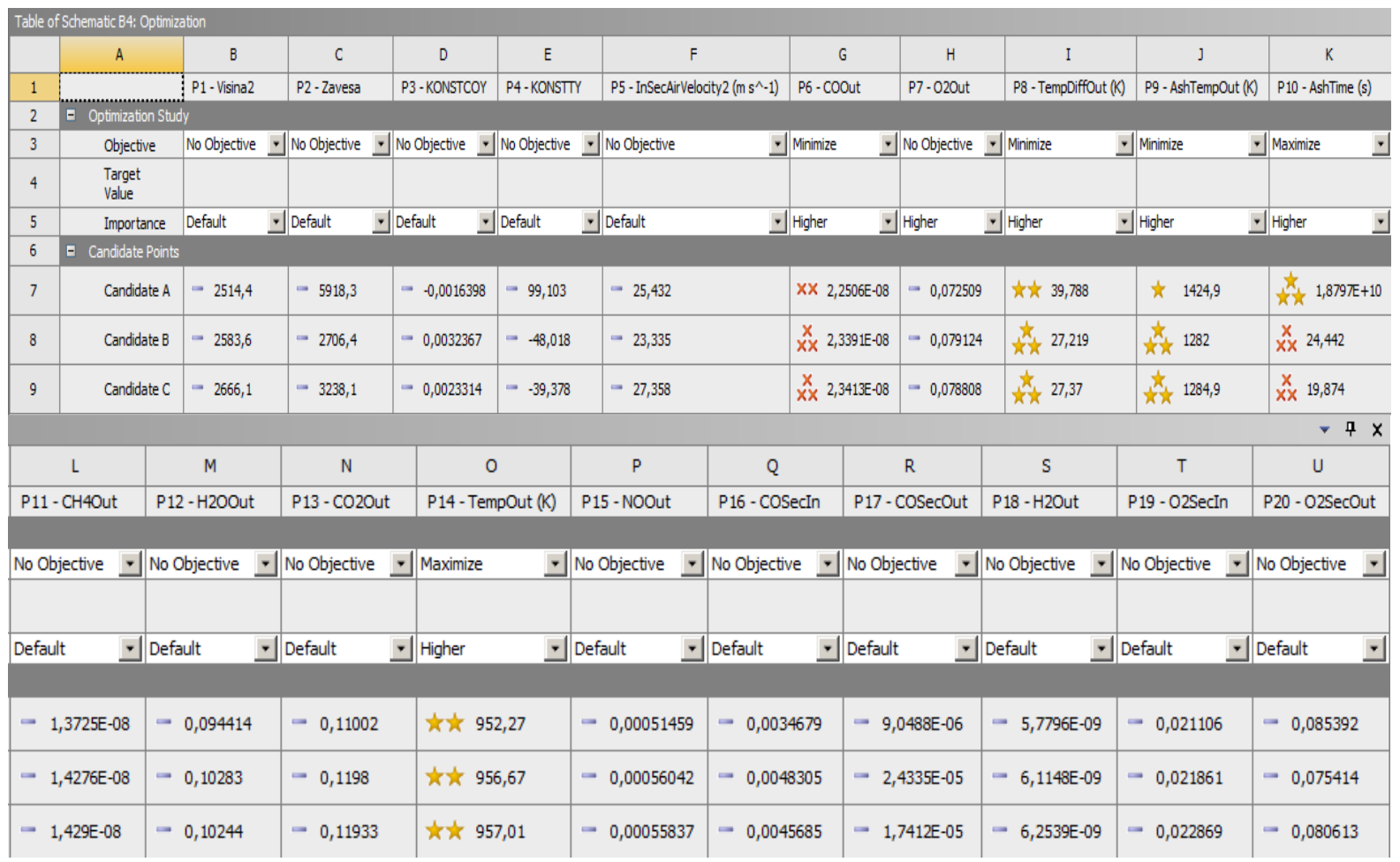


Once a GDO system has been introduced, the optimization study needs to be defined, which includes choosing the optimization method and setting the objectives. Then the optimization problem can be solved. In many cases, there will not be a unique solution to the optimization problem, and several candidates will be identified. The results of the optimization process is also very likely to provide candidates that cannot be manufactured (a radius of $3.14523 \mathrm{~mm}$ is probably hard to achieve!). But since all information about the variability of the output parameters is provided by the response surface, it becomes easy to find a design candidate close to the one indicated by the optimization process that will be acceptable.

As can be seen in Tale II, the objectives "minimize" and the importance "higher" were sep for output parameters P6-COOut, P8-TempDiffOut, and P9-AshTempMax, and on the other hand, the objectives "maximize" and importance "higher" were set for output parameters P10-AshTime and P14-TempOut, respectively. The objectives of the rest of the parameters were stayed on "no objectives". The most important thing was to avoid the inhomogeneous temperature field before the outlet and to reduce the ash temperature due to the heat inhomogeneous temperature load of the heat exchangers and to exceed the ash melting point which prevent are very dangerous that the WTEP operates safety and reliable. Finally, the candidate B has been chosen which had the P8-TempDiffOut the lowest and the value of the rest parameters were the most convenient. The results for the input parameters value and their corresponding output parameters value can be read in appropriate row for the candidate in this table. The results of this optimization are shown in Figure 7 and discuss on Chapter 4.

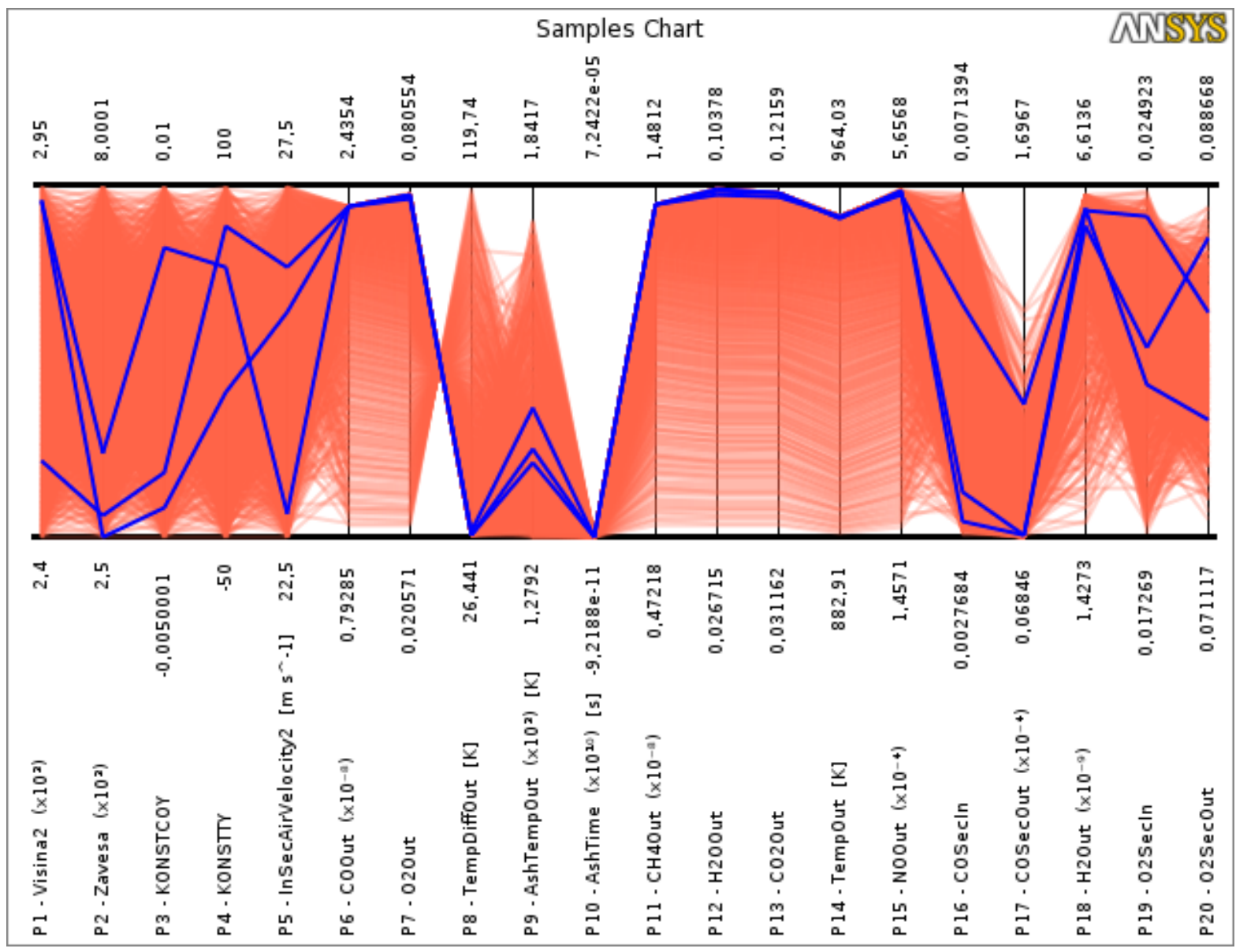

Figure 6: Samples chart with the tree best candidates visualization.

The results of screening sampling method and the final candidates are shown in Figure 6 graphically. As can be seen, the samples, which were created through the whole area (from 
lower to upper value) of the input parameters, were taken into account and the candidates were final chosen through decisions support system (Chapter 3.2).

As a good practice, it is also recommended to check the accuracy of the response surface for the design candidates. To do so, the candidate should be verified by a design point update, so as to check the validity of the output parameters

\subsection{Decision support system [15]}

Decisions support system is a goal-based, weighted, aggregation-based design ranking technique. Given $n$ input parameters, $m$ output parameters, and their individual targets, the collection of objectives is combined into a single, weighted objective function, $\Phi$, which is sampled by means of a direct Monte Carlo method using uniform distribution The candidates designs are subsequently ranking by ascending magnitudes of the value $\Phi$. By continuous input parameters, the proposed function $\Phi$ is given by the following:

$$
\Phi=\sum_{i=1}^{n} w_{i} N_{i}+\sum_{j=1}^{m} W_{j} M_{j}
$$

where:

$$
\begin{aligned}
& W_{i} \text { and } w_{j}=\text { weight } \\
& N_{i} \text { and } M_{j}=\text { normalized objectives for input and output parameters, respectively }
\end{aligned}
$$

The normalized objectives are:

$$
\begin{aligned}
& N i=\left(\frac{\left|x_{t}-x\right|}{x_{u}-x_{l}}\right)_{i} \\
& M j=\left(\frac{\left|y_{t}-y\right|}{y_{\text {max }}-y \min }\right)_{j}
\end{aligned}
$$

where:

$x=$ current value for the input parameter

$x_{t}, y_{t}=$ coresponding target value

$y=$ current value for the output parameter

$x_{l}$ and $x_{u}=$ lower and upper values, respectively, for the input parameter i

$y_{\min }$ and $y_{\max }=$ corresponding lower and upper bonds, respectively, for output parameter j

The fuzziness of the combined objective function derives from weights $w$, which are simply defined as follows:

$$
w_{i}=w_{j}= \begin{cases}1.000, & \text { if the Importance is "Higher" } \\ 0.666, & \text { if the Importance is "Default" } \\ 0.333, & \text { if the Importance is "Lower" }\end{cases}
$$

The targets represent the desired values of the parameters, and are defined for the continuous input parameters as follows: 


$$
x_{t}=\left\{\begin{array}{cl}
x & \text { if Objective is "No Objective" } \\
x_{l} & \text { if Objective is "Minimize" } \\
1 / 2\left(x_{l}+x_{u}\right), & \text { if Objective is "Seek Midpoint" } \\
x_{u} & \text { if Objective is "Maximize" }
\end{array}\right.
$$

and, for the output parameters we have to the following desired values:

$$
y_{t}=\left\{\begin{array}{cl}
y & \text { if Obiective is "No Obiective" } \\
y_{\min } & \text { if Objective is "Minimize" and a "Target" value is not defined } \\
y_{t}^{*} & \text { if Objective is "Values <= Target" and "Target is defined and } \mathrm{y} \geq \mathrm{y}_{\mathrm{t}}^{*} \\
y & \text { if Objective is "Values <= Target" and "Target is defined and } \mathrm{y} \leq \mathrm{y}_{\mathrm{t}}{ }^{*} \\
y_{t}^{*} & \text { if Objective is "Seek Target" or "Values = Target" } \\
y & \text { if Objective is "Values }>=\text { Target" and "Target is defined and } \mathrm{y} \geq \mathrm{y}_{\mathrm{t}}^{*} \\
y_{t}^{*} & \text { if Objective is "Values }>=\text { Target" and "Target is defined and } \mathrm{y} \leq \mathrm{y}_{\mathrm{t}}^{*} \\
y_{\min } & \text { if Objective is "Maximize" and a "Target" value is not defined }
\end{array}\right.
$$

where:

$$
\mathrm{Y}_{\mathrm{t}}^{*}=\text { user-specified target value }
$$

From the normed values it is obvious that the lower the value of $\Phi$, the better design with the respect to the desired values and importance. Thus, a quasi-random uniform sampling of design points is done by Hammersley algorithm and the samples are sorted in ascending order of $\Phi$. The desired number of designs is the drawn from the top of the sorted list. A crowding technique is employed to ensure that any two sampled design points are not very close to each other in the space of the input parameters.

\section{Ranking candidates design point:}

Each parameter range is divided into 6 zones, or rating scales. The location of a design candidate value in the range is measured according to the rating scales. For example, for parameter $X$ with a range of 0.9 to 1.1 for a design candidate value of 1.0333 is calculated as follows:

$\left(((\text { Absolute }(1.0333-1.1)) /(1.1-.9))^{*} 6\right)-(6 / 3)=-1$ [signed with one star]. As 0 indicating neutral, negative values indicated closer to the target, up to -3 ; positive value indicating father away from the target, up to +3 . Following the same procedures, we will get rating scale for design candidate value of 0.9333 as $5.001-3=+2$ [two crosses], that means away from a target.

Therefore, the extreme cases are as follows:

1. Design Candidate value of 0.9 (the worst), the ranking scale is $6-3=+3$ [three crosses]

2. Design Candidates value of 1.1 (the best), the rating scale is $0-3=-3$ [three stars]

3. Design Candidates value of 1.0 (neutral), the rating scale is $3-3=0$ [dash]

With decision support system, the analyzes and the right decisions can be made quickly and easily. 


\section{RESULTS AND DISCUSSIONS}

As a result of the previous work (Table III), the initial and optimized input parameters values can be found out (Table IV). For the comparison between initial values optimized input parameters values, the convergent CFD calculation with optimized values had to be made. One of the results of this comparison and final work are shown in Figure 7.

Table IV: Initial and optimized values of input parameters review.

\begin{tabular}{|c|c|c|c|c|}
\hline$\#$ & Parameter mark & $\begin{array}{c}\text { Initial } \\
\text { value }\end{array}$ & $\begin{array}{c}\text { Optimized } \\
\text { value }\end{array}$ & Unit \\
\hline P1 & Visina2 & 2.683 & $2.583,6$ & {$[\mathrm{~mm}]$} \\
\hline P2 & Zavesa & 8.000 & $2.706,4$ & {$[\mathrm{~mm}]$} \\
\hline P3 & KONSTCOY & 0 & 0,0032367 & {$[-]$} \\
\hline P4 & KONSTTY & 0 & $-48,018$ & {$[\mathrm{~K}]$} \\
\hline P5 & InSecAirVelocity2 & 25 & 23,335 & {$[\mathrm{~m} / \mathrm{s}]$} \\
\hline
\end{tabular}
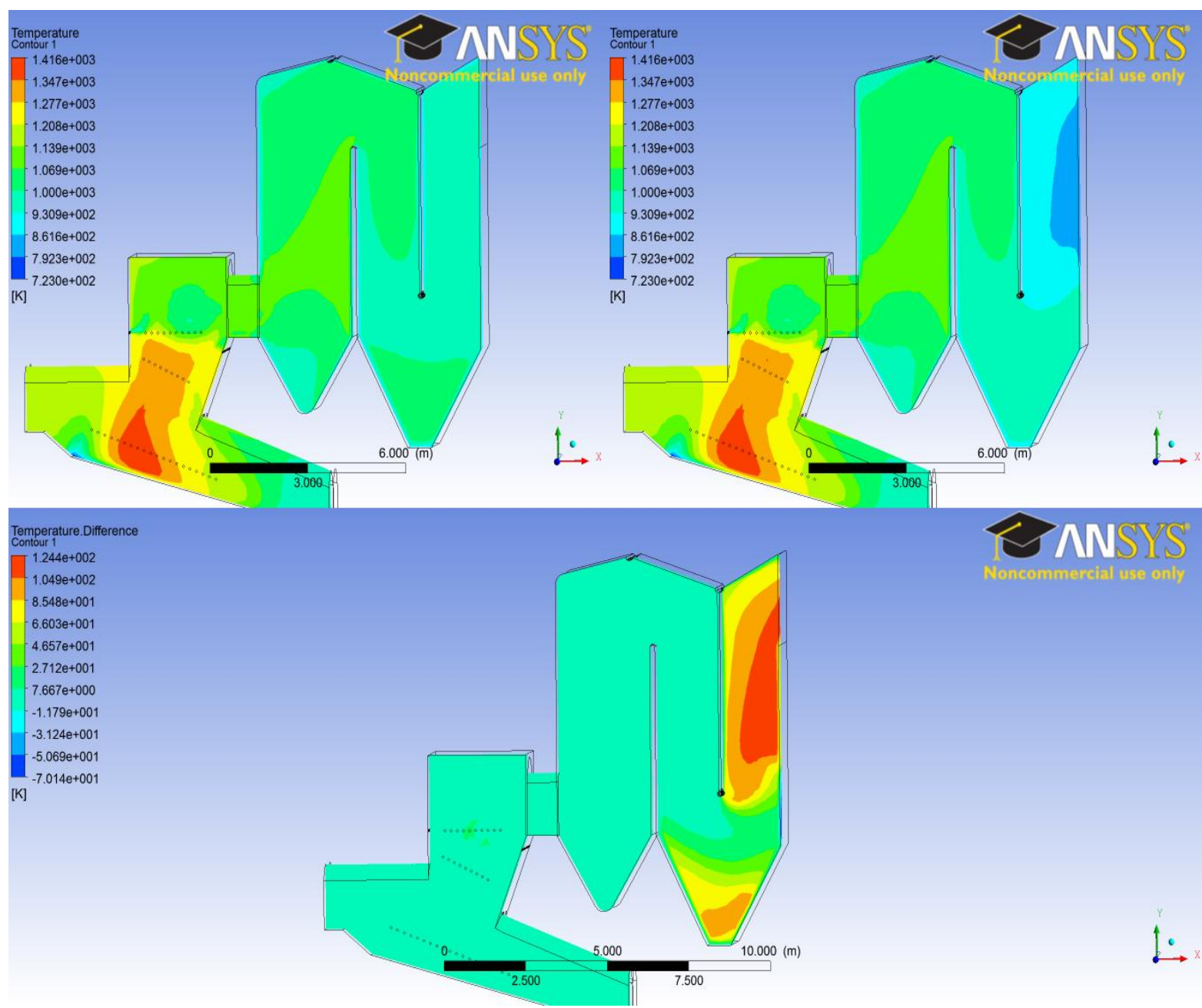

Figure 7: Temperature profile comparison between optimized input values (upper left), initial values (upper right) and difference between these values. 
On the Figure 7, the comparison between optimized input values, initial values and differences between these values is shown. The temperature inhomogeneous at the outlet can be seen in the simulation with initial input values (upper left) and on the other hand, the temperature homogeneous with optimized values (upper left). The temperature difference (lower) grows up to between $66 \mathrm{~K}$ and $124 \mathrm{~K}$ and became more homogeneous. These are better conditions in order to avoid troubles with heat exchangers and ash melting point deposit.

The comparison can be shown with other parameters such as reactants or product-fields of the combustion, velocity fields, streamlines, travelling time, ash tracking, ash-residence time and much more. On this basis, the further analyzes can be made and final resolution can be judged and supervised. Unfortunately, the frame of this paper is limited, so further results can be waited upon so other time.

\section{CONCLUSIONS}

The CFD simulation and optimisation is an appropriate tool to solve the respective problems of MSW combustion. With design exploration the limitations of a single design point exceeded because the whole area of the input parameters and their combinations with relevant output parameters can be taken into account. In the final stage the GDO helps us to achieve the most appropriate operating conditions and/or combustion chamber geometry which are chosen through efficient design support system. Furthermore, the interaction among input and output parameters can be establish in order to find their local sensitivity and their parametric correlations.

With this approach the costs and time in the development and research phase can be reduced, and also the most convenient support in these activities. In future work, different and more input parameters can be employed to find out further results of design investigation.

\section{REFERENCES}

[1] Hans - Heinz Frey; Bernhard Peters; Hans Hunsinger; Jürgen Vehlow (2003). Characterization of municipal solid waste combustion in a grate furnaces, Waste Management, Vol. 23, 689-701

[2] Ligang Liang; Rui Sun; Jun Fei; Shaohua Wu; Xiang Liu; Kui Dai; Na Yao (2008). Experimental study of effects of moisture content on combustion characteristics of simulated municipal solid wastes in fixes bed, Bioresource Technology, Vol. 99, 7238-7246

[3] Dipl. - Ing. Dipl. - Wirt. - Ing. Christian Wolf (2005). Erstellung eines Modells der Verbrennung von Abfall auf Rostsysytemen unter besonderer Burücksichtigung der Vermischung - ein Beitrag zur Simulation von Abfallverbrennungsanlagen, Dissertation, Universität Duisburg-Essen

[4] Y. B. Yang; Y. R. Goh; R. Zakaria; V. Nasserzadeh; J. Swithenbank (2002). Mathematical modelling of MSW incineration on a travelling bed, Waste Management, Vol. 22, 369-380

[5] Yao Bin Yang; Vida N. Sharifi; Jim Swithenbank (2007). Converting moving - grate incineration from combustion to gasification - Numerical simulation of the burning characteristics, Waste Management, Vol. 27, 645-655

[6] Yao Bin Yang; Jim Swithenbank (2008). Mathematical modelling of particle mixing effect on the combustion of municipal solid wastes in a packed-bed furnace, Waste Management, Vol. $28,1290-1300$

[7] C. N. Lim; Y. R. Goh; V. Nasserzadeh; J. Swithenbank; O. Riccius (2001). The modelling of solid mixing in municipal waste incinerators, Powder Technology, Vol. 114, 89-95

[8] X. L. Haui; W. L. Xu; Z. Y. Qu; Z. G. Qu; Z.G. Li; F. P. Zhang; G. M. Xiang; S. Y. Zhu; G. Chen (2008). Numerical simulation of municipal solid waste combustion in a novel two - stage reciprocation incinerator, Waste Management, Vol. 28, 15-29

[9] W. Blasiak; W. H. Yang; W. Dong (2006). Combustion performance improvement of grate fired furnace using Ecotube system, Journal of the Energy Institute, Vol. 79, No. 2, 67-74 
[10] Hans - Heinz Frey; Bernhard Peters; Hans Hunsinger; Jürgen Vehlow (2003). Characterization of municipal solid waste combustion in a grate furnaces; Waste Management, Vol. 23, 689-701

[11] Wein Dong (2000). Design of Advanced Industrial Furnaces Using Numerical Modelling Method, Doctoral Thesis, Heat and Furnace Technology, Department of Materials Science and Engineering, Royal Institute of Technology, 10044 Stockholm, Sweden

[12] Changkook Ryu; Donghoon Shin; Sangmin Choi: Bed combustion and gas flow model for MSW incinerator, Department of Mechanical Engineering, Korea Advanced Institute of Science and Technology, Yusong-gu, Taejon, Korea, 305-701

[13] Filip Kokalj; Niko Samec; Leopold Škerget (2005). An Analysis of the Combustion Conditions in the Secondary Chamber of a Pilot - Scale Incinerator Based on Computational Fluid Dynamics, Strojniški vestnik - Journal of Mechanical Engineering, Vol. 51, No. 6, 280-303

[14] Software package: ANSYS, Inc. Workbench 13.0, Users Help, 2010

[15] ANSYS Inc., Customer portal, from https://www1.ansys.com/customer/default.asp, accessed on 14-04-2009 